\title{
Genetic Engineering -Tool for Mankind
}

\author{
Shashwat Mandal, and Christian Bach
}

\begin{abstract}
This study was conveyed to send a driven research of Genetic Engineering its Tools, Applications, as well as Ethics which are some of the areas of Genetic Engineering which has impact on human life. Some people think Genetic Engineering as a boon where as some people think genetic engineering are way to interrupt the natural process. The motivation behind this paper is to show a review to discuss some of factors in Genetic Engineering that makes Genetic Engineering a need for mankind. The main goal of the study was to inspect various Tools, Application along with Ethics in Genetic Engineering as a tool for mankind
\end{abstract}

Index Terms - Genetic Engineering; Tools; Recombination; Risks; Application.

\section{INTRODUCTION}

There is numerous of literature on Genetic Engineering [1]-[9]. Genetic Engineering has been around for a period which has now been an important part of Human life as it has enhanced the living standard with regards to health care, food, medicine as well the environment. According to [10], Genetic engineering is an alternation or change in natural process where genetic potential is acknowledged and changed into facts. According to [11] Genetic engineering, involves the group of techniques that is used to slice and rejoin the DNA, especially DNA from different biological species, and subject the resulting hybrid DNA to form new combinations of heritable genetic material [11]. Genetic Engineering has advantages as well as disadvantages but how mankind uses it is in their own hand. So, taking the benefits of Genetic Engineering for development of different sectors should be considered with all the perspective of everyone so there is less controversy about the Genetic Engineering.

The point of the paper is to give a calculated hypothetical system which are based on the articles and journals in Genetic Engineering. For scientific purpose, Genetic Engineering has been taken as a central part of the study and divided into three parts which are Tools of Genetic Engineering, Application of Genetic Engineering and its Risk [12]-[40]. The article covers three main areas of Genetic Engineering which should be looked upon with great interest so that we can get more knowledge about Genetic Engineering and how to use for betterment of mankind.

This study focuses to contribute the areas where Genetic Engineering is proven to be a boon for mankind and there is

Published on March 23, 2018.

Shashwat Mandal is with the University of Bridgeport, Bridgeport, CT USA (e-mail: shashwatmandal@gmail.com).

Christian Bach is with University of Bridgeport, Bridgeport. He is now with the Department of Technology Management, CT 06604 USA (e-mail: cbach@.bridgeport.edu). lot of possibilities for the application of Genetic Engineering to enhance the areas that is still not developed from which mankind can take maximum benefits. The application of Genetic Engineering will help mankind to solve various problems related to food, health, medicines as well as the environment. Thus, the study offers some important perception for giving out a framework model which highlights the importance of Genetic Engineering along with the tools, its application and the risk associated with it.

This report has been composed in following way, the undertaking research technique and after that the reliant variable which is trailed by the three factors alongside the connection between them as far as survey driven research strategy utilizing the examination [41]. Finally, it will display the commitment to the examination and decision gives a rundown and evaluate of the discoveries which will help to identify areas for further research.

\section{RESEARCH METHODS}

A comprehensive literature review on Genetic Engineering created a theoretical foundation of the paper. Using the grounded theory, a model was developed. This is a timely topic as the new shape of recent environmental regulation appears to be strict. A new model is presented to encapsulate highly dynamic interaction of Genetic engineering and Application, Tools of Genetic Engineering, and Risk that reflect what is the benefits of Genetic Engineering, what are its tools, as well as risk associated with it.

The exploration techniques utilized as a part of this examination takes after the standards illustrated by [41]. It is an extensive writing audit on Genetic Engineering-an apparatus for humanity. More than sixty articles have been inspected in pertinent diaries such us JSTOR, Science Direct, and others which made a hypothetical establishment of the paper. Three techniques are for Genetic Engineering that have been recognized as fundamental instruments.

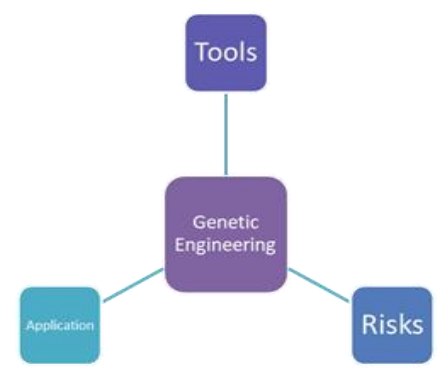

Fig. 1. Factor associated with Genetic Engineering 


\section{DISCUSSION}

Genetic engineering is about intervention in natural process in which the hidden potentialities are realized [10]. The genetic engineering can be used for healing purposes in different situations [38]. Genetic engineering is used to excise the genetic material from one organism and transfer into the other one with new genetic material [42]. The genetic engineering is also known as Recombinant technology that is used to cut and join genetic material, mainly DNA and introduce it into another organism creating hybrid DNA [11]. There is a huge difference in field such as medicines agricultures [2]. Genetic engineering is used to cut move and transfer DNA from one organism to another [6].

\section{A. Tools of Genetic Engineering}

The author mentions that genetic engineering is about intervention in natural process in which the hidden potentialities are realized [10]. The genetic engineering can be used for healing purposes in different situations [38]. Genetic engineering is used to excise the genetic material from one organism and transfer into the other one with new genetic material [42]. The genetic engineering is also known as Recombinant technology that is used to cut and join genetic material, mainly DNA and introduce it into another organism creating hybrid DNA [11]. There is a huge difference in field such as medicines agricultures [2]. Genetic engineering is used to cut move and transfer DNA from one organism to another [6].

Due to advances in the genetic tools the future of genetic engineering is very bright, and much more can be done in this field [3]. The genetic tools can help to solve the problems concerned with interpreting the genetic evidence and importance of interdisciplinary efforts [35]. By using the genetic tools in proper way, it can be proving to be beneficial and surprising in many situations [16]. Medical urgent conditions such as immunodeficiency can be diagnosed and treated using genetic tools such as Gene therapy [24]. With the development in high resolutions molecular genetic tools have given attention to process that contributes to decline of plant and animals' populations [43]. Somatic hybridization is one of the easiest and efficient methods for genetic characterization [44].

The knowledge that behind the Recombinant DNA Technology is to cut plasmid DNA into fragments, recombined the fragments with DNA ligase enzymes and transformed bacteria with the recombinants is what the recombinant technology is all about [45]. The utilization of Recombinant DNA Technology is for separation and replication of a one organism and addition of it into another species After then the host cell is having new characteristics to secrete protein for which the gene was inserted. [27]. The Recombinant DNA particles is an innovation that is utilized to exchange outside gens and duplicate them at sub-atomic level profoundly changed the possibility of recombinant DNA research and innovation which has turned out to be a standout amongst the most intense instruments for subatomic science and a promising device for Genetic Engineering which could fabricate valuable quality items on of it into another species which is a host cells [46]. Genetic engineering or Recombinant DNA technology used for alteration of the DNA of a cell so that it produces a protein which naturally occurs in another organism [12]. Recombinant DNA Technology is the process of constructing a DNA molecule which usually involves the combination of a specific DNA of interest for one species, the donor, with that of an appropriate vector which may be plasmid, bacteriophage or virus [8].

The biolistic process is used for the transformation of foreign material from diverse organisms including the animal cells and tissues to another organism [47]. Biolistic is the immediate and reproducible innovation which offers an option for DNA free genome altering advances in which qualities can be fitted to suit the coveted catalyst which should achieve the coveted tissue which in a host cells [48]. The Biolistic process also known as microprojectile bombardment that which is a certified method for DNA delivery into the various species [49]. Biolistic has been successfully used to insert the nucleic acid into different organisms which are not amenable tore traditional methods of transfection [13].

Electroporation is a simple technique that is used of altering the genetic makeup of the organism which induces genetic material in the membrane using high voltage electrical fields for short time. This type of phenomenon avoids disadvantages of substance, mechanical, and viralactuated combination methodology, for example, cell lethality, have go confinement, or in the constraint on the quantity of cells that can be intertwined [50]. Apart from Biolistic and Agrobacterium-mediated transformations, electroporation is other technique which is used insertion of DNA to generate new types of organism [51]. Electroporation is done by short application of highintensity electric fields of permeable bio membranes which is commonly used to transfer genetic membrane into plant protoplast along with mammalian cells [52]. The use of an extreme electric field crosswise over cell films adjusts the electric potential contrast over the layer which brings about the pore development, that permits the presentation of exogenous material into the phone, this procedure is known as electroporation [18]

\section{B. Application of Genetic Engineering}

In 1960s an experiment on dwarf wheat and rice was one of the most significant modification in plants [26]. The genetic tools are used to identify the genetic structure and population of big horn sheep [19]. Population $n$ or landscape-scale Eco toxicological has lag far behind despite the advances in genetic engineering [29]. The molecular genetics is used for bear research its conservation and management [53]. Foreign and viral protein via negative strands can have biotechnological applications [54]. Logic regression is technique that is used to build Boolean rules which is used to get more accurate data for genetic engineering. PRIM stands for Patient rule induction method which is used to find sub regions in the input space with low values for target value and extreme regression is used [40].

On the planet just about $90 \%$ of the human nourishment supply is just given by 15 crops species which is modest number out of 10-30 million species which is habiting in our biosphere, presenting qualities shape different creature and live stock has been viewed as a promising approach to 
upgrade the efficiency [55]. Gene manipulation $\mathrm{n}$ the agriculture goes very far ahead because novel plant species are bread that can never evolve in the biosphere, molecular biologist are looking for the perfect genetic combinations that can help to breed plants with increment in disease resistance, tolerance to stress, content of protein as well as self-fertilization [4]. A couple of years back the specialists found that Agrobacterium tumefaciens because crown irritate tumors in plant by exchanging a bit of DNA from a bacterial plasmid into plant cells which led to conclusion that plasmid can be utilized to convey valuable qualities into plant for its profitability [56]. Food shortages exist on the planet as the human population is expanding quicker than the sustenance generation capacity of the agricultural products, introduction of the Genetic engineering can help to reduce this problem to certain extent [57].

The genetic engineering could be used to manufacture the various animal proteins of commercial value as it involves introducing genes into natural DNA sequences to force cells to make protein that would not ordinarily be made such as manufacturing of Rennin, ab endangered protein used in cheese making [58]. In the animal breeding there are and now techniques for achieving the result like producing a grazing animal suitable for Central Africa as well as other regions [10]. Genetic engineering can be used to isolate a gene from a different source and transferred into a chromosome of a living cell so that the gene can directly synthesize a specific protein [5]. The involvement of Genetic Engineering has enhanced dairy cows that produce more milks, horses that are large larger and stronger, hundreds of dogs of different shapes and sizes which are able to hunt or fight, sheep dogs to protect the herd [7]. The new range of technology is very huge, the cloning, developing life exchange, sex determination by using Genetic Engineering for animal product efficiency, improving quality of food that we consume, for production of pharmaceutical medicine as well as organ transplantation in human patients [59].

With the introduction of genetic Engineering into the health sector human insulin, development hormone as well as interferon are manufactured by the bacteria cells and gained insights into principals of cell functions, the underlying characteristics of tumor virus along with genetic disease [60] The public will be at the greatest benefits of as the fear of the genetic engineering will be replaced with a welcoming of blessings which come from genomic research which will lead to exciting new ear in medicine impacting the health of humankind [39]. The genetic technology is so precise that it will allow us to design children by elimination of genetic disease and enhance individual life [20]. The new genetic technologies are applied medicines which happens with regards to public interest with possibility of more compelling treatment of human ailment [61]. Since the finish of the Human Genome Project, doctor and researchers have found better treatment of patients, for example, now researcher can relate an illness with a genetic expression [62].

\section{Risks}

The fundamental issue is that advances in learning don't consequently characterize the criteria for their utilization.
Accordingly, we find that about the greater part of our logical information has the capability of being "great" or "terrible," contingent on man's use of it [63]. In the debates about our utilization of hereditary science, the most clear and persuasive good dream has emerged in the positions of those contradicted to human hereditary designing in any form, for whatever reason and risk associated with it [64].

The questions that brings ecologists to center stage in the debate is simple: how organisms will be carrying altered or new genes relate to the evolution and ecological interrelationships of indigenous organisms when introduced to natural environments [65]. The Biotechnology is going to confront major obstacles in near future, easing the perils of abiotic stretch which are salinity, dry season and temperatures, involving bug control, upkeep and improvement of nature, quality of foods as well as release of genetic material into the environment [1]. This exploration administering, the direction and observing of hereditarily designed microorganism and infections discharged into the earth, the perils related with discharging GEMs into nature are the creation and advancement of new technology which harms the environment and non-target species [25]. The widespread planting of the genetically modified crops has yet to be sanctioned, the prospect that highlights the public worries to both the environmental and health issue, implications of genetically modified organism, the application of genetic engineering in the production of novel agricultural products raises significant concern for protection of the environment [9].

Recent research was carried to understand public attitudes towards biotechnology and more specifically, genetic engineering which has focused on attitudes towards the use of the technology rather than its specific application concerning about the ethical issues [23]. Human enhancement has recently become controversial topic in bioethics, question about human enhancement has been a major concern in many peoples [15]. Many projects in other areas like agricultural, medical and engineering ethics; recombinant DNA research and energy related projects, are also concerned with social impact where ethics comes into major play [33]. At first, the Human Genome Project seems to be ungoverned by any explicit ethical or legal norms, however from its beginning the HGP has spawned a myriad of international, regional and national reports and guidelines and more legislation [36]. An important part of the discussion is consideration of the ethical issues, so far, the debate on the ethics of genetic engineering has been vigorous and reasonably well informed, in many ethical issues raised by genetic engineering they were only able to list many possible kinds of consequences [66].

\section{RESUlts}

The conformation from this study leads to fact that Genetic Engineering is growing a great significance in development of human life along with animal and plants. Application of genetic Engineering can be used in various areas and new technology can also be developed that will enhance the quality of life. For several years such as Recombinant Technology, Biolistic and Electroporation is used to transfer genetic material into other organism to get a 
desired gene product. There is also risk, and benefits concerned with genetic engineering. The result of the study is shown in Fig.2. where the structure created is introduced including every one of the factors examined in this research

\section{Genetic Engineering-Tool for mankind}

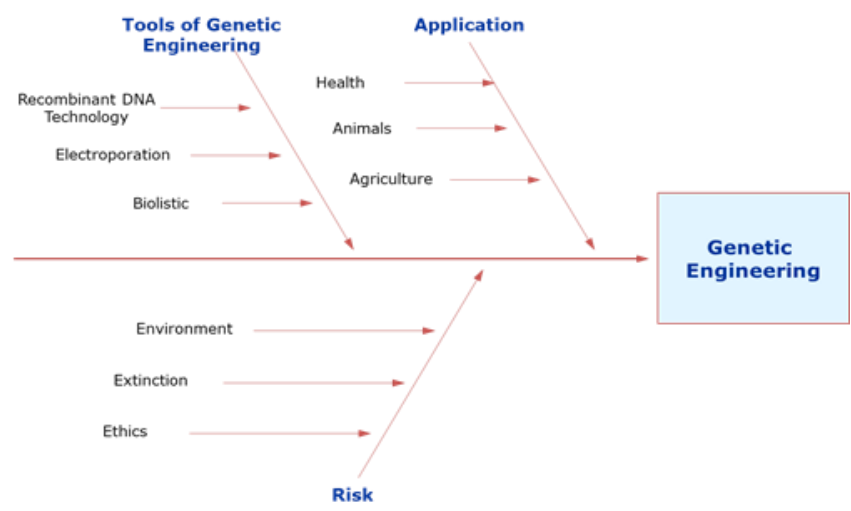

Fig. 2. Proposed framework model of relationship between key factors to determine Genetic Engineering

\section{CONTRIBUTION AND NEW INSIGHT}

With reviewing the literature, we can agree that the Genetic Engineering is a technology that can make our life easier by enhancing the quality of food that we consume, the medicine we intake, the animal products that we eat, the agricultural products that we use in daily life. Genetic engineering uses technology such as Recombinant DNA Technology, Biolistic method and Electroporation. This literature also covers the risk associated with Genetic Engineering. The ethical as well as the environmental risk associated with Genetic Engineering is discussed in the literature. While modifying any genes of an organisms, the effect on the environment as well as the ethical concern should be kept in mind. The use of Genetic Engineering should be done carefully as it affects the environment and has many ethical issues. There is some limitation to this literature as only some of the factors are considered here and many more are not discussed. Therefore, there needs to be more research on this topic and the topic should be analyzed in more detail to get good information about the different factors of Genetic Engineering.

\section{CONCLUSION}

This study is a good topic because the researcher can build up a superior comprehension of Genetic Engineering as it can be used for betterment of human life with the advancement in new technology related to Genetic Engineering. The applications of the Genetic Engineering as well as its different tools along with different tools should be considered for betterment of mankind.

This model is based on different articles which is about the different factors of Genetic Engineering such as tools of Genetic Engineering, application of Genetic Engineering as well as the risk associated to Genetic Engineering.

Since the research has accomplished its objectives, there are few unavoidable limitations. These data are related to just sixty articles as well as the researches. The result of the research provides us with ways to utilize the Genetic Engineering for betterment of mankind and to understand risk associated with it.

\section{ACKNOWLEDGMENT}

The writer would express his thankfulness to Christian Bach, Ph.D., educator at University of Bridgeport, Technology Writing Communication and Research class, who gave knowledge, aptitude and consolation that enormously helped me with this research.

\section{REFERENCES}

[1] Altman, A., From Plant Tissue Culture to Biotechnology: Scientific Revolutions, Abiotic Stress Tolerance, and Forestry. In Vitro Cellular \& Developmental Biology. Plant, 2003. 39(2): p. 75-84.

[2] Blank, R.H., Politics and Genetic Engineering. Politics and the Life Sciences, 1992. 11(1): p. 81-85.

[3] Boake, C., et al., Genetic Tools for Studying Adaptation and the Evolution of Behavior. The American Naturalist, 2002. 160(S6): p S143-S159.

[4] Bodd, xe, and Tineke, Beltsville Symposium: Genetic Engineering in Agriculture: Another Green Revolution? BioScience, 1982. 32(7): p. 572-575.

[5] Brill, W.J., Genetic Engineering Applied to Agriculture: Opportunities and Concerns. American Journal of Agricultural Economics, 1986. 68(5): p. 1081-1087.

[6] Burke, D., Genetic engineering. RSA Journal, 1999. 148(5491): p. 38 47.

[7] Chan, S., Should we enhance animals? Journal of Medical Ethics, 2009. 35(11): p. 678-683.

[8] Charles, L.V. and G.S. William, Recombinant DNA: History of the Controversy. The American Biology Teacher, 1979. 41(8): p. 480491.

[9] Christopher, P.R., Liability for the Release of GMOS into the Environment: Exploring the Boundaries of Nuisance. The Cambridge Law Journal, 2003. 62(2): p. 371-402.

[10] Waddington, C.H., GENETIC ENGINEERING. Journal of the Royal Society of Arts, 1975. 123(5225): p. 262-272.

[11] Rosenberg, E., Chapter 10 - Genetic Engineering, in It's in Your DNA2017, Academic Press. p. 81-93.

[12] Cripps, Y., Recombinant DNA Technology. A Patent Case in the House of Lords. The Cambridge Law Journal, 1997. 56(2): p. 262267.

[13] Davis, R.E., et al., Transient Expression of DNA and RNA in Parasitic Helminths by Using Particle Bombardment. Proceedings of the National Academy of Sciences of the United States of America, 1999. 96(15): p. 8687-8692.

[14] Dehghanpour, H.R., P. Parvin, and S. Abdolahi, Performance enhancement of solar panel by surface texturing using ArF excimer laser. Optik - International Journal for Light and Electron Optics, 2015. 126(24): p. 5496-5498.

[15] Delaney, J.J., Possible people, complaints, and the distinction between genetic planning and genetic engineering. Journal of Medical Ethics, 2011. 37(7): p. 410-414.

[16] DeYoung, R.W. and R.L. Honeycutt, The Molecular Toolbox: Genetic Techniques in Wildlife Ecology and Management. The Journal of Wildlife Management, 2005. 69(4): p. 1362-1384.

[17] Dub, et al., Rigor in Information Systems Positivist Case Research: Current Practices, Trends, and Recommendations. MIS Quarterly, 2003. 27(4): p. 597-636

[18] Ephrem, T., R.D. Astumian, and P.B. Chock, Selective and Asymmetric Molecular Transport Across Electroporated Cell Membranes. Proceedings of the National Academy of Sciences of the United States of America, 1994. 91(24): p. 11512-11516.

[19] Epps, C.W., et al., Using Genetic Tools to Track Desert Bighorn Sheep Colonizations. The Journal of Wildlife Management, 2010. 74(3): p. 522-531.

[20] evans, j.h., a brave new world? how genetic technology could change us. Contexts, 2003. 2(2): p. 20-25.

[21] Flavell, R., Transformation of Plant Science in Our Time: The Contribution of Jozef S. Schell (1935-2003). Plant Physiology, 2003. 132(3): p. 1119-1121. 
[22] Flavell, R.B., Plant Biotechnology and Its Application to Agriculture. Philosophical Transactions of the Royal Society of London. Series B, Biological Sciences, 1989. 324(1224): p. 525-535.

[23] Frewer, L.J., C. Howard, and R. Shepherd, Public Concerns in the United Kingdom about General and Specific Applications of Genetic Engineering: Risk, Benefit, and Ethics. Science, Technology, \& Human Values, 1997. 22(1): p. 98-124.

[24] Friedmann, T., <strong>How Close Are We to Gene Doping? $</$ strong $>$. The Hastings Center Report, 2010. 40(2): p. 20 22.

[25] Giddings, G., Tansley Review No. 99. The Release of Genetically Engineered Micro-Organisms and Viruses into the Environment. The New Phytologist, 1998. 140(2): p. 173-184.

[26] Gottlieb, L.D., The Genetic Basis of Plant Form. Philosophical Transactions of the Royal Society of London. Series B, Biological Sciences, 1986. 313(1159): p. 197-208.

[27] Greenfield, M.S., Recombinant DNA Technology: A Science Struggling with the Patent Law. Stanford Law Review, 1992. 44(5): p. 1051-1094.

[28] Gupta, S. and N. Sharma, CSR- A Business Opportunity. Indian Journal of Industrial Relations, 2009. 44(3): p. 396-401.

[29] Haig, S.M., et al., Genetic Applications in Avian Conservation. The Auk, 2011. 128(2): p. 205-229.

[30] Harjoto, M.A. and H. Jo, Corporate Governance and CSR Nexus. Journal of Business Ethics, 2011. 100(1): p. 45-67.

[31] Hashiguchi, S. and H. Morishima, Estimation of Genetic Contribution of Principal Components to Individual Variates Concerned. Biometrics, 1969. 25(1): p. 9-15.

[32] Heywood, J.S., Spatial Analysis of Genetic Variation in Plan Populations. Annual Review of Ecology and Systematics, 1991. 22: p 335-355.

[33] Hollander, R.D. and N.H. Steneck, Science- and Engineering-Related Ethics and Values Studies: Characteristics of an Emerging Field of Research. Science, Technology, \& Human Values, 1990. 15(1): p. 84 104

[34] Jagpal, H.S. and I.E. Brick, The Marketing Mix Decision under Uncertainty. Marketing Science, 1982. 1(1): p. 79-92.

[35] Jobling, M.A., The impact of recent events on human genetic diversity. Philosophical Transactions: Biological Sciences, 2012. 367(1590): p. 793-799.

[36] Knoppers, B.M. and R. Chadwick, The Human Genome Project: Under an International Ethical Microscope. Science, 1994. 265(5181): p. 2035-2036.

[37] Koornneef, M., C. Alonso-Blanco, and A.J.M. Peeters, Genetic Approaches in Plant Physiology. The New Phytologist, 1997. 137(1): p. $1-8$.

[38] Kwasikpui, D.B., Genetic Engineering. BioScience, 1971. 21(4): p. 162-162.

[39] Larson, J.S., MEDICINE, GOVERNMENT, AND THE HUMAN GENOME. Journal of Health and Human Services Administration, 2001. 24(3): p. 321-330.

[40] LeBlanc, M. and C. Kooperberg, Boosting predictions of treatment success. Proceedings of the National Academy of Sciences of the United States of America, 2010. 107(31): p. 13559-13560.

[41] LePine, J.A. and A. Wilcox-King, Developing novel theoretical insight from reviews of existing theory and research. Academy of Management Review, 2010. 35(4): p. 506-509.

[42] Genetic Engineering: A Mammalian First. Science News, 1976 109(15): p. 231-231.

[43] Snow, A.A. and P.G. Parker, Molecular Markers for Population Biology. Ecology, 1998. 79(2): p. 359-360.

[44] Pinto, F.M., C. Yves, and V.M. Cabrera, Molecular Genetic Characterization of Plant Somatic Hybrids. In Vitro Cellular \& Developmental Biology. Plant, 1995. 31(2): p. 96-100.

[45] Linda, D., Teaching Recombinant DNA Technology in High School Biology Courses. The American Biology Teacher, 1988. 50(6): p 368-373.
[46] Yi, D., Cancer, Viruses, and Mass Migration: Paul Berg's Venture into Eukaryotic Biology and the Advent of Recombinant DNA Research and Technology, 1967-1980. Journal of the History of Biology, 2008. 41(4): p. 589-636.

[47] xc, et al., A New Approach for the Biolistic Method: Bombardment of Living Nitrogen-Fixing Bacteria into Plant Tissues. In Vitro Cellular \& Developmental Biology. Plant, 2003. 39(5): p. 443-449.

[48] Martin-Ortigosa, S., et al., Mesoporous Silica Nanoparticle-Mediated Intracellular Cre Protein Delivery for Maize Genome Editing via loxP Site Excision. Plant Physiology, 2014. 164(2): p. 537-547.

[49] Russell, J.A., M.K. Roy, and J.C. Sanford, Major Improvements in Biolistic Transformation of Suspension-Cultured Tobacco Cells. In Vitro Cellular \& Developmental Biology. Plant, 1992. 28P(2): p. 97 105.

[50] Sally, L.V.W. and J.A. Saunders, Electrofusion and Electroporation of Plants. Plant Physiology, 1992. 99(2): p. 365-367.

[51] Mitchell, T.D., et al., Electroporation-Mediated Transient Gene Expression in Intact Cells of Sweetpotato. In Vitro Cellular \& Developmental Biology. Plant, 1998. 34(4): p. 319-324.

[52] Miller, J.F., W.J. Dower, and L.S. Tompkins, High-Voltage Electroporation of Bacteria: Genetic Transformation of Campylobacter jejuni with Plasmid DNA. Proceedings of the National Academy of Sciences of the United States of America, 1988. 85(3): $\mathrm{p}$ 856-860.

[53] Waits, L.P., Molecular Genetic Applications for Bear Research. Ursus, 1999. 11: p. 253-260.

[54] Palese, P., et al., Negative-Strand RNA Viruses: Genetic Engineering and Applications. Proceedings of the National Academy of Sciences of the United States of America, 1996. 93(21): p. 11354-11358.

[55] Paoletti, M.G. and D. Pimentel, Genetic Engineering in Agriculture and the Environment. BioScience, 1996. 46(9): p. 665-673.

[56] Marx, J.L., Ti Plasmids as Gene Carriers. Science, 1982. 216(4552) p. 1305-1305.

[57] Pimentel, D. and M. Pimentel, Population Growth, Environmental Resources, and the Global Availability of Food. Social Research, 1999. 66(1): p. 417-428.

[58] Designer Genes down on the Farm. Science News, 1981. 119(22): p. 342-342.

[59] Mepham, T.B., Transgenesis in Farm Animals: Ethical Implications for Public Policy. Politics and the Life Sciences, 1994. 13(2): p. 195 203.

[60] Genetic Engineering For Medicine. British Medical Journal (Clinical Research Edition), 1981. 282(6259): p. 169-170.

[61] Schibeci, R., et al., Genetic Medicine: An Experiment in CommunityExpert Interaction. Journal of Medical Ethics, 1999. 25(4): p. 335 339.

[62] Liebman, M.N., Macroscope: An Engineering Approach to Translational Medicine. American Scientist, 2005. 93(4): p. 296-298.

[63] Nagle, J.J., The Dilemma of Genetic Engineering. Journal of Religion and Health, 1972. 11(4): p. 370-376.

[64] Boone, C.K., Moral Fantasy in Genetic Engineering. The American Biology Teacher, 1984. 46(8): p. 449-456.

[65] Singer, E., A. Corning, and M. Lamias, Trends: Genetic Testing, Engineering, and Therapy: Awareness and Attitudes. The Public Opinion Quarterly, 1998. 62(4): p. 633-664

[66] Murray, T.H., Ethical Issues in Genetic Engineering. Social Research, 1985. 52(3): p. 471-489.

Shashwat Mandal, was born in Nepal in 1990.He obtained his bachelor's degree in Bachelor of Technology in Biotechnology form Himalayan White House International College. He is currently a full-time student pursuing his M.S. in Technology Management at University of Bridgeport. His research area of interest is in Genetic Engineering. 